\title{
Do shifting baselines in natural history knowledge threaten the environment?
}

\author{
Simon R. Leather · Donald J. L. Quicke
}

Published online: 20 October 2009

(C) Springer Science+Business Media, LLC 2009

In an early guest editorial, the Duke of Westminster (1991) wrote of the conflict between human population pressure and the preservation of the countryside highlighting the pivotal role that science would play in mediating this conflict. His editorial was a modified version of a speech he gave to graduates and their guests at the Award and Degree ceremony of environmental scientists at Farnborough College of Technology, Hampshire UK on 12th December, 1990. His message to these embryonic environmental analysts and conservation managers was that they were the torch-bearers of the future and guardians of the countryside. The message was clear: to protect the environment one must be able to comprehend and recognise its complexity and understand how its varied components interact and respond to change. To achieve this mission, we not only need a cohort of well-educated environmental scientists, but also a general population with a reasonable understanding of nature. It is becoming apparent that we are in danger of having neither.

Recently, we highlighted the lack of entomological and taxonomic training in the United Kingdom and its likely deleterious impact on the ability of future generations to make sense of the world around them (Leather 2007, 2009a, b; Leather and Quicke 2009). Similarly, Papworth et al. (2009) draw attention to the fact that due to the shifting baseline syndrome, whereby succeeding generations set their perceptions of change based on their own experiences rather than from those of previous generations (Pauly 1995), conservation efforts are likely to be jeopardised. This effect will even stretch to the conservation of

S. R. Leather $(\bowtie) \cdot$ D. J. L. Quicke

Division of Biology, Imperial College London,

Silwood Park Campus, Ascot SL5 7PY, UK

e-mail: s.leather@imperial.ac.uk charismatic mega-fauna. As Papworth et al. point out, if you are unaware of the change around you then how can you be expected to engage with the conservation of that environment? A good example of this is a possibly apocryphal story that was prevalent in the UK Forestry Commission in the 1990s. The story goes that in the 1950s during the major afforestation of upland Britain with exotic conifers, an area of moorland outside a small Scottish village, was earmarked for planting with North American lodgepole pine. The local inhabitants were not happy and the local newspaper was full of letters of protest complaining that the glorious scenery and dog walking opportunities would be ruined by the planned forest plantation. Needless to say, the plantation was duly established. Forty years later, it became due for harvesting. The local press was full of letters of protest from the nearby residents complaining that the glorious scenery and dog walking opportunities would be ruined by the planned harvesting operation. Human memories are indeed only a generation long. Environmental degradation on the other hand is probably permanent.

Just as alarming, is the disappearance of natural history both from school curricula (Leather and Quicke 2009) and from the daily experience of the general populace particularly those dwelling in urban environments; that is, the majority in all western countries (Cheeseman and Key 2007). This is having a devastating effect on the public knowledge base of plants and animals in general, and particularly of invertebrates (Leather 2009b). The situation for vertebrates is less desperate, although it is a sad fact that the most readily recognised mammals are likely to be exotics such as polar bears or tigers. In Germany, the general public's ability to recognise vertebrate species has apparently not changed since the 1980s (Randler 2008), although a mean recognition score of 20 out of 54, peaking 
at age 14 does not indicate a high degree of taxonomic awareness. On the plus side, frequent visitors to urban parks score significantly better than non-visitors (Randler et al. 2007). Of greater concern are the results of a survey carried out by OnePoll for the hotel chain Travelodge, and reported in the Daily Telegraph of 30th March 2009, which indicates that "More than half of Britons think the countryside is boring and that a third never even consider visiting rural areas." The survey also found that $10 \%$ were unable to identify a sheep, $44 \%$ could not identify an oak tree, $71 \%$ could not identify a pine tree, $74 \%$ could not identify a horse chestnut tree and $83 \%$ failed to recognise a bluebell, a stunning indictment of the lack of knowledge concerning plant life in Britain, something that we have also drawn attention to previously (Leather and Quicke 2009).

Among biology undergraduates with whom we have much recent experience at all levels, we have seen a very conspicuous decline in the average level of both zoological and botanical knowledge. Of course there are still a handful of students who were keen and knowledgeable naturalists even before entering college, but these people are now very much the exception. On a recent field course hardly 1 in 20 could recognise a plantain (Plantago) or dock (Rumex) as such. The great majority of those now studying for degrees in biology have had virtually no training or experience in identifying organisms, and sadly, the drive towards ever more molecular and hands-off meta-analysis type study in universities is exacerbating the situation. Although students may be enthused on a two-week long field course and get to learn to recognise a few major groups or species, without back-up, just as with use of statistics, for example, this will have little, if any, long term retention in their skill set.

All of the above is true despite an incredible improvement in the availability, affordability and quality of field guides and other identification aids over the past 30 or so years. These works make it possible for any enthusiastic person to identify virtually any macro-organism with a little practice and effort. And, it is from an ability to accurately identify organisms that other new discoveries can be made, not to mention the personal satisfaction that knowing about something delivers.

Yet go to any of the numerous natural history society meetings and field meetings around the UK and it is more than likely that the mean age of attendees will be considerable and young blood scarce. Being a bug-collector or flower-presser has not been cool since pre-mass television ownership, and even then it often took considerable resolve and zeal to make these into working hobbies from which more serious study was likely to arise. Nowadays, however, other factors play major roles that act against this sort of pursuit. Attitudes to collecting specimens (albeit with good motives), fear for children's' safety, the ready availability of a wealth of indoor entertainment, etc., appear successfully to have out-competed the development of love and learning about the organisms that surround us for so many people. The glossy natural history programmes that we occasionally see on the small screen, although widely discussed at the time, appear to have little lasting impact, as they are not reinforced by the general education system afforded to our young people. Unless we are able to rekindle a positive attitude towards appreciating nature in her entirety it will soon be too late to save the vast majority of species on our beleaguered planet.

\section{References}

Cheeseman OD, Key RS (2007) The extinction of experience: a threat to insect conservation? In Stewart AJA, New TR, Lewis OT (eds) Insect conservation biology. CABI, Wallingford, pp 322348

His Grace the Duke of Westminster (1991) A view from the countryside. The Environmentalist 11:3-4

Leather SR (2007) British entomology in terminal decline? Antenna 31:192-193

Leather SR (2009a) Little buzz about entomology. Times Higher Education, 15th January, 29.

Leather SR (2009b) Taxonomic chauvinism threatens the future of entomology. Biologist 56:10-13

Leather SR, Quicke DLJ (2009) Where would Darwin have been without taxonomy? J Biol Educ 43:51-52

Papworth SJ, Coad L, Rist J, Miller-Gulland EJ (2009) Shifting baseline syndrome as a concept in conservation. Conserv Lett 2:93-100

Pauly D (1995) Anecdotes and the shifting baseline syndrome of fisheries. Trends Ecol Evol 10:430

Randler C (2008) Pupil's factual knowledge about vertebrate species. J Baltic Sci 7:48-54

Randler C, Höllwarth A, Schaal S (2007) Urban park visitors and their knowledge of animal species. Anthrozoös 20:65-74 